\title{
Can Infundibular Height Predict the Clearance of Lower Pole Calyceal Stone After Extracorporeal Shockwave Lithotripsy?
}

\author{
M. Arzoz-Fabregas, L. Ibarz-Servio, F. J. Blasco-Casares, M. Ramon-Dalmau, F. J. \\ Ruiz-Marcellan
}

USP, Instituto Universitario Dexeus, Barcelona, Spain

\begin{abstract}
Purpose: To evaluate the efficacy of extracorporeal shock wave lithotripsy (SWL) on lower calyceal calculi in relation to the renal anatomical factors and determine which of these factors can be used to select patients who will benefit from SWL. Materials and Methods: We analyzed retrospectively 78 patients with single radiopaque lower calyceal stones treated with SWL. The patients were evaluated 3 months after lithotripsy with a simple abdominal X-ray and a kidney ultrasound scan. The success of the treatment, removal of all fragments, was correlated with renal anatomical factors measured in the pretreatment intravenous urography: infundibulopelvic angle, lower infundibulum width, lower infundibulum length, ratio length/width, infundibulum height, and number of minor calyces in the lower calyceal group.

Results: Three months after SWL treatment, 39 patients were stone-free (NR group) and 39 had residual fragments (R group). Both groups presented no differences in relation to infundibulopelvic angle, width and length of the lower calyceal infundibulum, length/width ratio of the lower infundibulum or number of lower calyces. Height of the infundibulum, described as the distance between the line passing through the lowest part of the calyx containing the calculus and the highest point of the lower lip of renal pelvis, was the only parameter in which significant differences $(p=0.002)$ were found between the NR and R groups.

Conclusions: Lower Infundibular height could be a good measurement tool for deciding which patients with lower calyceal lithiasis would benefit from SWL treatment. Height of less than $22 \mathrm{~mm}$ suggests a good outcome from lithotripsy.
\end{abstract}

Key words: kidney; kidney calculi; lithotripsy; anatomy; kidney calices

Int Braz J Urol. 2009; 35: 140-50

\section{INTRODUCTION}

The objective of SWL is to obtain a fragmentation of the calculus into fragments that can be expelled through the renal collecting system. However, the success of SWL also depends on the size and composition of the calculus, its location in the kidney, the anatomy of the urinary tract and some personal factors such as body mass index or patient mobility (1-4). According to Politis et al., although correct fragmentation is obtained in $98 \%$ of cases after SWL, the fragments are eliminated in only $75 \%$ (4).
Calculi in the lower calyceal group represent $24 \%-44 \%$ of all calculi requiring treatment (1). In this location, there are some controversial aspects as regards the efficacy of SWL, as the clearance rate is lower. It has been suggested that this phenomenon could be explained by an antigravitational position of the lower renal calyx $(1,5)$, On the other hand, residual fragments after SWL can cause complications such as chronic pain, obstruction, sepsis and re-growth, which occasionally require an interventionist approach. For these reasons, there is an obvious need for a method which helps us to decide which treatment is the best 
option for each individual patient: SWL, percutaneous surgery or flexible ureteroscopy $(1,3)$.

Different renal anatomic factors have been described since Sampaio et al. (1) first described the anatomy of the renal collecting system using three dimensional models and correlated the measurement of the infundibulopelvic angle with the success of SWL, including infundibular width and length, the infundibular width/length ratio, infundibular height, the number of minor calyces, the volume of the renal collecting system and the pattern of dynamic urinary transport (5-15). These measurements have been studied and correlated with the success of SWL with different results.

The objective of this study was to evaluate the outcome of SWL in patients with single lithiasis of the lower renal pole and correlated it with the aforementioned anatomical factors measured during the pre-treatment intravenous urography (IVU), in order to determine which of them could be an effective predictive factor to decide whether SWL could be successful.

\section{MATERIALS AND METHODS}

We performed a retrospective analysis of 78 consecutive patients with single radiopaque lithiasis of the lower calyceal group who were treated in only one session with a Dornier Lithotripter S during a two-year period (from June 2005 to June 2007).

Patients with more than one calculus, residual fragments after prior lithotripsy, urinary tract anomalies, prior surgical maneuvers, such as a double-J catheter, or reduced mobility were excluded.

All patients were treated by the same urologist under intravenous sedation.

The results of the treatment were evaluated 3 months after lithotripsy. Stone free status was defined as the absence of any residual fragments in a simple abdominal X-ray film and kidney ultrasound scan. Depending on whether there were remaining fragments after three months, the patients were divided into two groups: group NR, (non-residual) composed of patients free from calculi and group R (residual), composed of patients with residual fragments.
Personal details as gender, age, body mass index (BMI) and affected kidney were correlated for each patient with the existence or not of residual fragments after the treatment.

The following parameters, measured on the twenty minutes IVU pre treatment film in a supine position, were correlated with the existence or not of residual fragments three months after the treatment:

\section{Calculus Parameters}

Estimated surface area of the calculus $(\mathrm{SA})(\mathrm{mm} 2)$ : Measured at the pre-treatment simple abdominal X-ray. Result of multiplying the length (L) and width (W) diameters of the calculus by $\pi$ and by 0.25 (16). $\mathrm{SA}=\mathrm{L} \times \mathrm{W} \times \pi \times 0.25$

Number of shock waves applied: The number of shockwaves required to completely fragment the calculus was recorded in each case.

Calculus fragility index: Dividing the number of shock waves by the surface of the calculus in $\mathrm{mm} 2$.

Anatomical Parameters (measured at the pretreatment IVU)

Infundibular width $(\mathrm{mm})$ : The narrowest point on the axis of the lower infundibulum (Figure1).

Infundibular length (mm): Distance between the most distal point of the calyx containing the calculus and the midpoint of the lower lip of the renal pelvis (Figure-2).

Infundibular height ( $\mathrm{mm})$ : Distance between the horizontal line passing through the lowest part of the calyx containing the calculus and the highest point of the lower lip of the renal pelvis (Figure-3).

Infundibulopelvic angle $\left({ }^{\circ}\right)$ : The angle between the line drawn through the central axis of the lower infundibulum and the ureteropelvic axis (Figure-4).

Infundibular length/width ratio.

Number of minor calyces.

The statistical analysis was performed with the SPSS 13.0 Windows software program. We performed a descriptive analysis of all the aforementioned variables and compared them between the NR and R groups with Fisher's exact test and the 


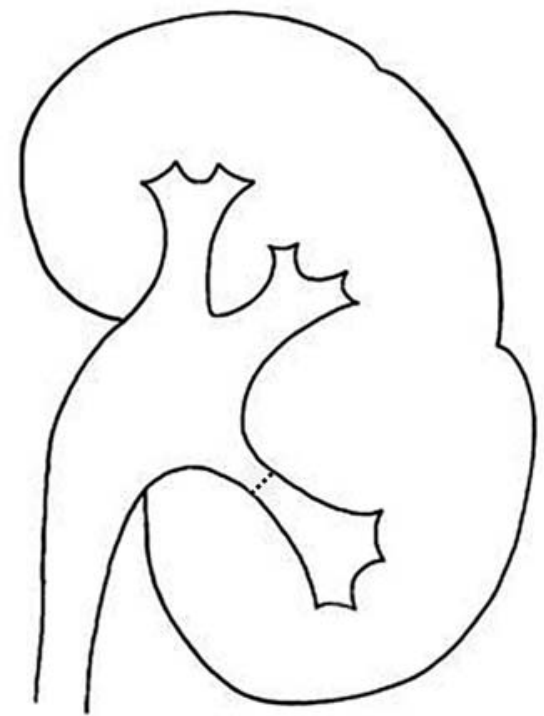

Figure 1 - Infundibular width ( $\mathrm{mm})$, measured as the narrowest point in the axis of the lower infundibulum.

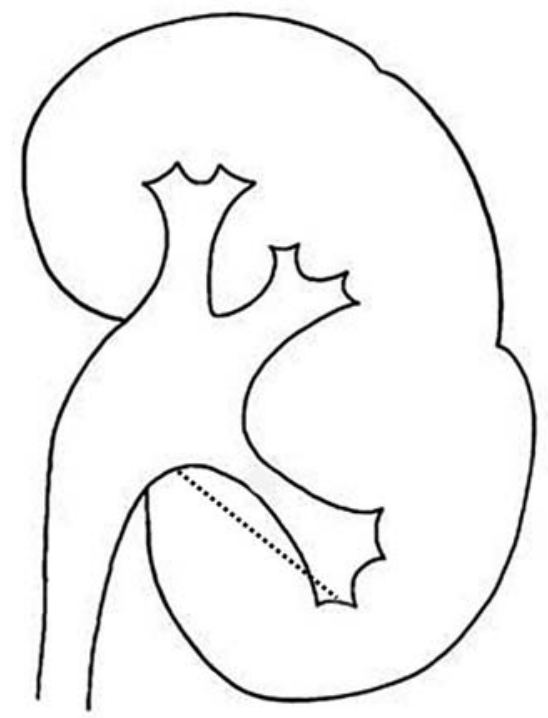

Figure 2 - Infundibular length $(\mathrm{mm})$, measured as the distance between the most distal point of the calyx containing the calculus and the midpoint of the lower lip of the renal pelvis.

Mann-Whitney-Wilcoxon U-test for the qualitative and quantitative variables, respectively. A logistic regression analysis was also performed to study the correlation of the existence of residual fragments with

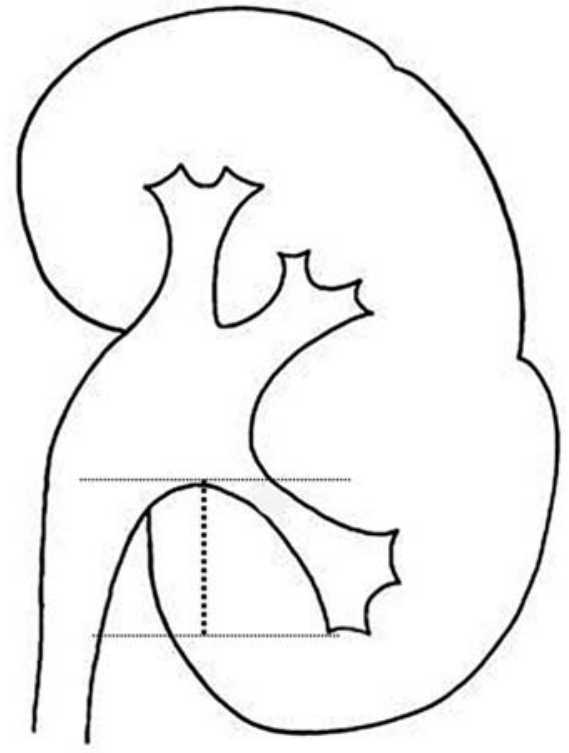

Figure 3 - Infundibular height ( $\mathrm{mm}$ ), measured as the distance between the horizontal line passing through the lowermost part of the calyx containing the calculus and the highest point of the lower lip of the renal pelvis.

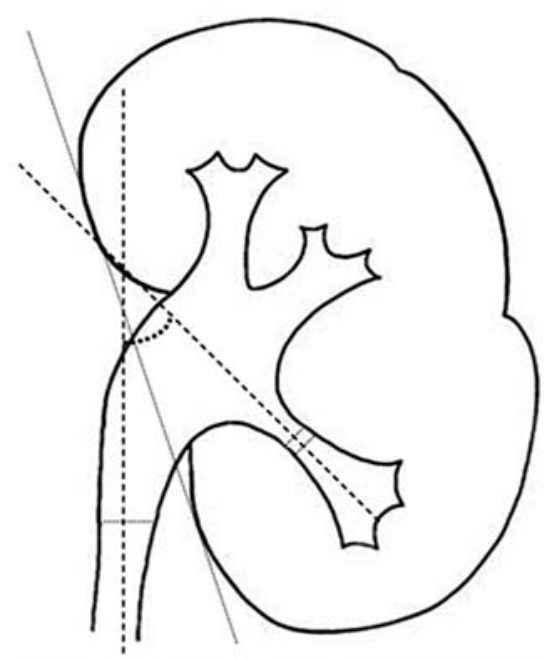

Figure 4 - Infundibulopelvic angle $\left({ }^{\circ}\right)$, described as the angle between the line drawn through the central axis of the lower infundibulum and the ureteropelvic axis.

all these parameters. Finally, a ROC curve was used to choose a cut-off point for the parameters showing significant differences in the logistic regression analysis. 


\section{RESULTS}

Seventy-eight patients were included in this study. Thirty-nine were classified in the NR group and the remaining thirty-nine in the $\mathrm{R}$ group.

Fifty per cent of the studied population was men and the other fifty per cent were women. The mean age of the patients was 48 (SD 13.4) years, and the mean BMI was $25.1 \mathrm{Kg} / \mathrm{m} 2$ (SD 4.8). Thirty-seven $(47.4 \%)$ of the calculi were located in the right kidney and forty-one $(52.6 \%)$ in the left. There were no significant differences regarding gender between NR and $\mathrm{R}$ groups (Table-1), but we found that women were more likely than men to eliminate all the fragments after SWL in our population ( $p=0.023)$.

The median surface area of the calculi was $63 \mathrm{~mm} 2$ (9-450), the median number of shockwaves required to fragment them was 2000 (1000-3300) and the median number of shock waves required to fragment one surface area unit (calculus fragility index) was 31.7 waves $/ \mathrm{mm} 2$ (111.1-7.3). Comparing the characteristics of the calculus between the two groups, there were no statistically significant differences (Table-1. Values are given as mean $\pm \mathrm{SD}$ ).

Concerning the anatomical measurements, no significant differences were found between the two groups when comparing infundibular length and width, infundibular length/width ratio, infundibulopelvic angle (IPA) or number of minor calyces. On the other hand, significant differences were found when comparing mean infundibular height in the two groups $(p=0.002)$, with less infundibular height found in patients who were stone-free after treatment (Table-1).

The logistic regression analysis for all the factors studied (personal, pertaining to the calculus and anatomical variables of the renal collecting system) show that only infundibular height had a significant impact on the absence of residual fragments and therefore, could be used as a predictive factor of the success of SWL in calculi located in the lower calyx (Table-2). Furthermore, the ROC curve shows that a

Table 1 - Patients, stone and collecting system anatomical parameters. Descriptive analysis for all patients and different groups. Correlation of all the variables between group NR (non-residual fragments) and group $R$ (residual fragments).

\begin{tabular}{lcccc}
\hline Parameters & All Patients & Group NR & Group R & p Value \\
\hline Sex (male: female, \%) & $50: 50$ & $36: 64$ & $64: 36$ & $0.023^{\mathrm{a}}$ \\
Age (years) & $48 \pm 13$ & $47 \pm 14$ & $50 \pm 13$ & $0.242^{\mathrm{a}}$ \\
Body mass index (Kg/m2) & $25.1 \pm 4.7$ & $24.9 \pm 5.4$ & $25.2 \pm 4$ & $0.515^{\mathrm{b}}$ \\
Stone side (right: left, \%) & $47.4: 52.6$ & $56.4: 43.6$ & $37.5: 61.5$ & $0.173^{\mathrm{a}}$ \\
Stone area (mm2) & $86.1 \pm 70.5$ & $84.4 \pm 76.5$ & $87.8 \pm 64.8$ & $0.745^{\mathrm{b}}$ \\
Number of shock waves & $2097.1 \pm 651.8$ & $2167.9 \pm 567.2$ & $2026.3 \pm 727.4$ & $0.473^{\mathrm{b}}$ \\
Stone fragility (No./mm2) & $35.2 \pm 24.5$ & $39.9 \pm 30.5$ & $30.4 \pm 15.3$ & $0.189^{\mathrm{b}}$ \\
Infundibulum width (mm) & $6.5 \pm 8.2$ & $6.4 \pm 8.5$ & $6.7 \pm 7.9$ & $0.781^{\mathrm{b}}$ \\
Infundibulum length (mm) & $25.9 \pm 6.7$ & $24.6 \pm 4.9$ & $27.2 \pm 7.9$ & $0.101^{\mathrm{b}}$ \\
Infundibulum length/ width ratio & $7.8 \pm 6.2$ & $6.4 \pm 3.9$ & $9.2 \pm 8.6$ & $0.380^{\mathrm{b}}$ \\
Infundibulum height (mm) & $24.1 \pm 7$ & $21.7 \pm 5.6$ & $26.6 \pm 7.4$ & $0.001^{\mathrm{b}}$ \\
Infundibulopelvic angle $\left({ }^{\circ}\right)$ & $51.9 \pm 13.4$ & $51.8 \pm 11.6$ & $52 \pm 15.1$ & $0.505^{\mathrm{b}}$ \\
Number of minor calyx (\%) & $43.8: 56.5$ & $50: 50$ & $37.2: 62.8$ & $0.349^{\mathrm{a}}$ \\
1 vs. $>$ 1 & & & & \\
\hline
\end{tabular}

Values are given as mean $\pm S D,{ }^{a}$ for categorical parameters statistical analysis with Fisher exact test was done; ${ }^{b}$ for quantitative variables a U-Mann-Whitney Wilcoxon sum rank test analysis was done. 
Table 2 - Logistic regression analysis.

\begin{tabular}{|c|c|c|c|c|c|c|}
\hline & B & E.T. & Wald & gl & Sig. & $\operatorname{Exp}(B)$ \\
\hline Age & -0.003 & 0.027 & 0.013 & 1 & 0.911 & 0.997 \\
\hline BMI & 0.034 & 0.084 & 0.169 & 1 & 0.681 & 1.035 \\
\hline Stone area & 0.006 & 0.007 & 0.749 & 1 & 0.387 & 1.006 \\
\hline Number of waves & 0.000 & 0.001 & 0.410 & 1 & 0.522 & 1.000 \\
\hline Fragility & 0.036 & 0.025 & 2.044 & 1 & 0.153 & 1.037 \\
\hline I. width & -0.045 & 0.043 & 1.115 & 1 & 0.291 & 0.956 \\
\hline I. length & -0.034 & 0.065 & 0.275 & 1 & 0.600 & 0.967 \\
\hline Length / width & -0.055 & 0.081 & 0.471 & 1 & 0.493 & 0.946 \\
\hline I. height & -0.144 & 0.072 & 3.997 & 1 & 0.046 & 0.866 \\
\hline IPA & -0.018 & 0.024 & 0.554 & 1 & 0.457 & 0.982 \\
\hline Sex & -0.991 & 0.658 & 2.273 & 1 & 0.132 & 0.371 \\
\hline Constant & 3.071 & 2.818 & 1.188 & 1 & 0.276 & 21.569 \\
\hline
\end{tabular}

$B M I=$ body mass index; $I=$ infundibulum; $I P A=$ infundibulopelvic angle.

height between 22 and $24 \mathrm{~mm}$, and specifically 22.5 $\mathrm{mm}$ of height value could be the best cut-off point in our population for predicting response to treatment with an approximate sensitivity and specificity of $70 \%$ (Figure-5).

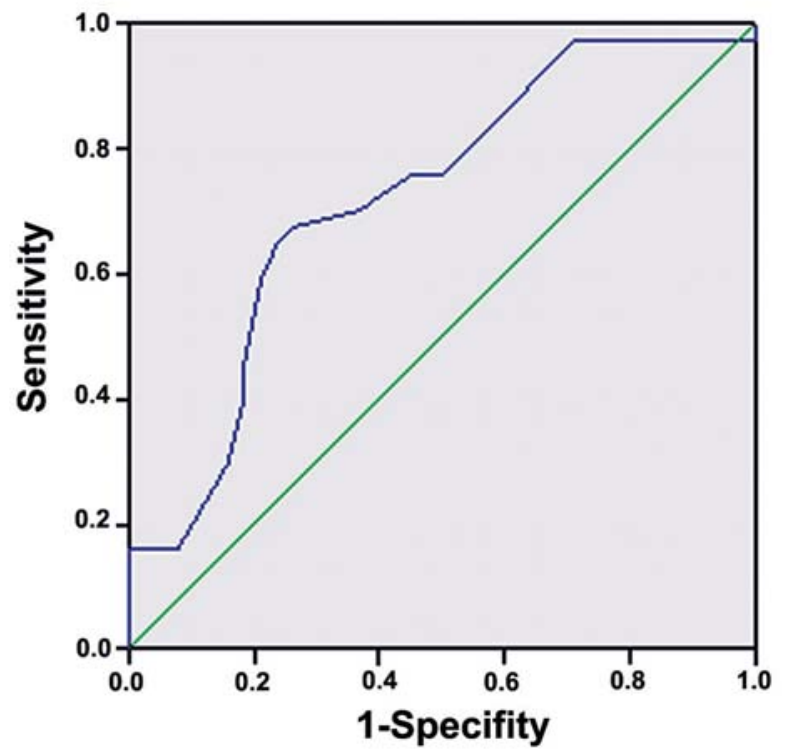

Figure 5-ROC curve of cut-off points for infundibular height ( $\mathrm{mm})$.
ROC Curve Coordinaters

\begin{tabular}{ccc}
\hline Infundibulum Height & Sensitivity & Specifity \\
\hline 4.00 & 1.000 & 1.000 \\
6.00 & 0.973 & 1.000 \\
9.00 & 0.973 & 0.974 \\
12.50 & 0.973 & 0.947 \\
16.00 & 0.973 & 0.895 \\
18.50 & 0.973 & 0.737 \\
19.50 & 0.973 & 0.711 \\
20.50 & 0.757 & 0.500 \\
21.50 & 0.757 & 0.447 \\
22.50 & 0.703 & 0.368 \\
28.60 & 0.676 & 0.268 \\
24.50 & 0.649 & 0.237 \\
25.50 & 0.495 & 0.211 \\
26.50 & 0.595 & 0.184 \\
27.50 & 0.405 & 0.184 \\
29.00 & 0.297 & 0.158 \\
31.00 & 0.162 & 0.079 \\
32.50 & 0.162 & 0.000 \\
34.00 & 0.135 & 0.000 \\
37.50 & 0.081 & 0.000 \\
42.00 & 0.054 & 0.000 \\
45.00 & 0.027 & 0.000 \\
47.00 & 0.000 & 0.000 \\
\hline & & \\
\hline
\end{tabular}




\section{COMMENTS}

Since SWL appeared in the 1980s, most renalureteral calculi previously eligible for open surgery or blind endoscopic maneuvers have been successfully treated with few complications (3). However, with the development of new therapeutic techniques such as percutaneous nephrolithotomy (PCNL) or flexible ureteroscopy, the use of SWL in some situations, such as lithiasis located in the lower calyceal group, is controversial.

The objective of this study was to evaluate a population with single radiopaque lithiasis in the lower calyx, treated by SWL and fragmented into expellable particles in a single session. Depending on the response to treatment evaluated at three months with simple abdominal X-ray and kidney ultrasound scan, we divided the patients into two groups and compared them in relation to the factors which could be related to fragment expulsion, with emphasis on anatomical variables, in order to determine which of them would enable us to predict the success of SWL, thus ruling out patients who would not benefit from this treatment and who could be eligible for other therapeutic procedures such as ureteroscopy, PCNL or control of evolution $(17,18)$.

The purpose of SWL is to disintegrate the stone into fragments of an expellable size $(<4 \mathrm{~mm})$, in which success represents the complete elimination of all fragments (3). However, this often depends on factors affecting the particular patient, factors related to the calculus and factors related to the anatomy of the renal collecting system $(1,3,4)$.

With reference to the size of lithiasis for which PCNL should be used, instead of SWL in lithiasis of the lower pole, continues to be subject to debate. Albala et al., in a multicenter prospective study analyzing lithiasis located in the lower renal pole, reached the conclusion that only calculi smaller than $1 \mathrm{~cm}$ are eliminated in $50 \%$ of cases after lithotripsy, and they proposed that the cut-off point for deciding between PCNL and SWL should be $1 \mathrm{~cm}$ (5). On the other hand, with the development of new flexible ureteroscopes, remains debated whether SWL should be the optimal choice of treatment for calculi in the lower calyceal group measuring less than $1 \mathrm{~cm}$. Pearl et al., in the second phase of Lower Pole Study Group, conducted a prospective, randomized study to compare treatment by SWL and ureteroscopy of lithiasis $<1 \mathrm{~cm}$ in the lower pole, without finding statistically significant differences (18). In our study, we analyzed patients with lithiasis with a median surface area of $63 \mathrm{~mm} 2$ (9-450), equivalent to $8 \mathrm{~mm}$ diameter (3-21), which were fragmented into expellable fragments in a single session, as the objective was to evaluate the anatomical factors which could have an impact on fragment expulsion, instead of studying the effect of the size of the lithiasis on said expulsion. Moreover, we found no significant differences between the NR and $\mathrm{R}$ groups in relation to the surface area of the calculus, the number of shock waves required to fragment the stones or their fragility, measured as the number of waves divided by the surface area of the calculus.

Concerning the location of the calculus, there is some controversy concerning the efficacy of SWL, especially in lithiasis of the lower calyceal group, where a large percentage of calculi are not eliminated, regardless of their size or composition. This phenomenon is believed to be due to an antigravitational problem, which could be related to the anatomy of the calyx. The earliest studies of the anatomy of the lower calyceal group were conducted by Sampaio et al., who used polyester endocasts of cadaveric kidneys to study the length of the lower infundibulum, the width of the calyx and the IPA. According to these authors., patients with an IPA of more than $90^{\circ}$ are more likely to eliminate the fragments after treatment with SWL $(1,19)$. There have subsequently been more studies, such as Elbahanasy et al., who performed a retrospective analysis of the urograms examinations performed before SWL of lithiasis smaller than $15 \mathrm{~mm}$ in the lower calyceal group, showing that patients with a larger IPA, shorter infundibular length and greater infundibular width are those who most often eliminate the fragments after the treatment (9). Similar to Elbahanasy et al. studies we used urograms examinations before SWL in order to measure the intrarenal geometry and to find if there was any relationship with this anatomy and the stone-free status after SWL and thus classify patients into favorable or unfavorable for SWL.

Pace et al. (20) after analyzing the infundibular width on the 5, 10, 20 and compression films in supine 
position, on the prone film and a film after voiding in erect position concluded that the compression film followed by the 10 and 20 minute films are the most suitable to estimate the maximum diameter of the infundibulum. In our study, we used the 20 minute film in a supine position in all the patients in order to avoid different measurements of each anatomic factor owing to the dynamic of the collecting system. To avoid the interobserver variation of different measurement described previously by Knoll et al. (2), all the parameters in our study where evaluated by the same urologist.

Despite the fact that most of the studies of the lower pole anatomy use urograms pre-treatment examinations to measure anatomic factors, it has been discussed that some of these factors like infundibular width or infundibular height should not be used because its measurement can change with different urography phases, respiration and/or postural movements or poor quality images $(7,20,21)$. As we were more used to evaluating the collecting system by urography in the period when the study was done, we decided to perform this exploration on all the patients included in the study. Although there have been some groups that evaluated the possibility of using a three dimensional helical computed tomography to measure the anatomy of the collecting system to avoid potential bias as described above instead of using an urography some authors did not find any statistical difference which concluded that IVU remains a good method to analyze renal collecting system $(20,22)$. IPA is the most widely measured factor when evaluating the anatomy of the collecting system and it has been measured using several methods. Sampaio et al. $(1,19)$ calculated the angle according to the location of the lithiasis, whereas Elbahanasy et al. (9) calculated the IPA based on precise and reproducible anatomical references, which seem more appropriate for defining the route to be followed by stone fragments located in the inferior pole. We have therefore used this method to measure the IPA in our study.

In our population, we found no statistically significant differences between the two groups when comparing infundibular length and width, the length/ width ratio, the IPA or the number of minor calyces (Table-1). Indeed, both in the univariate and logistic regression analyses we found that only infundibular height $(\mathrm{p}=0.002)$ had a significant impact on calculus elimination and that it could be used to predict the success of SWL in lithiasis of the inferior pole. These results are similar to those of Tuckey et al. who, in order to simplify calculation of the renal collecting system, analyzed the height of the infundibulum, found that patients with a calyx height of $<15 \mathrm{~mm}$ eliminated the fragments in $95 \%$ of the cases, whereas patients with a calyx height of $>15 \mathrm{~mm}$ only do so in $52 \%$ of cases (15). Although this variable is easy to measure compared with others such as the IPA and it is reproducible without requiring a bevel protractor to measure it, some groups disregard it because they believe that the measurement could vary in each urography according to the patient's respiratory movements and postural changes (7). Sorensen et al. found a statistically significant difference in a wide range of infundibular height (less than $15 \mathrm{~mm}$ or more than 30 $\mathrm{mm}$ ) defined for stones less than $10 \mathrm{~mm}$ (14). Poulakis et al. used an artificial neural network in order to determine which anatomic measurements could predict the stone free status after SWL. They found that infundibular height was one of the most important variables to predict it with an excellent reproducibility of this measurement (11). More recently, another study performed by Symes et al. proved that infundibular height is useful to predict the success rate after SWL when treating lower pole renal stones less than $20 \mathrm{~mm}$ (13).

Unlike Tuckey et al. (15), who used a $15 \mathrm{~mm}$ cut-off point to predict which patients were candidates for SWL, we analyzed all the possible cut-off points with a ROC curve, finding that the points with highest sensitivity and specificity in our population were between $22 \mathrm{~mm}$ and $24 \mathrm{~mm}$ of infundibular height. The real cut-off point in our ROC curve, with optimal sensibility and specificity, was $22.5 \mathrm{~mm}$, but we reduced it to $22 \mathrm{~mm}$ because clinically it is very difficult to measure $0.5 \mathrm{~mm}$. Using the value of $22 \mathrm{~mm}$ as a cut-off, in our population we found that $68.6 \%$ of patients with an infundibular height less than 22 $\mathrm{mm}$ were stone-free and only $35 \%$ of patients with an infundibular height higher than $22 \mathrm{~mm}$ were free from fragments. In agreement with Tuckey and Poulakis we suggest that this is one of the most easily and reproducible anatomic factors to measure when evaluating the lower pole and should be considered. Although 
our results are promising further prospective studies comparing IVU and CT scans, with a larger number of patients are warranted to confirm our data.

\section{CONCLUSIONS}

After analyzing all the aforementioned anatomical factors, our data suggests that the height of the calyx could be used in our population to predict which patients with lithiasis in the lower calyceal group would benefit from treatment with SWL. As the parameter is easy to calculate in outpatients without the need for specific instruments, it is certainly of great interest for consideration in future studies. Although we have found a possible range of cut-off points for distinguishing between these patients, further prospective studies with a larger number of patients are required to confirm our data.

\section{CONFLICT OF INTEREST}

None declared.

\section{REFERENCES}

1. Sampaio FJ, D'Anunciação AL, Silva EC: Comparative follow-up of patients with acute and obtuse infundibulum-pelvic angle submitted to extracorporeal shockwave lithotripsy for lower caliceal stones: preliminary report and proposed study design. J Endourol. 1997; 11: 157-61.

2. Knoll T, Musial A, Trojan L, Ptashnyk T, Michel MS, Alken P, et al.: Measurement of renal anatomy for prediction of lower-pole caliceal stone clearance: reproducibility of different parameters. J Endourol. 2003; 17: 447-51.

3. Eisenberger F, Bub P, Schmidt A: The fate of residual fragments after extra-corporeal shock wave lithotripsy. J Endourol 1992; 6: 217-8.

4. Politis G, Griffith DP: ESWL: stone-free efficacy based upon stone size and location. World J Urol 1987; 5: 255-8.

5. Albala DM, Assimos DG, Clayman RV, Denstedt JD, Grasso M, Gutierrez-Aceves J, et al.: Lower pole I: a prospective randomized trial of extracorporeal shock wave lithotripsy and percutaneous nephrostolithotomy for lower pole nephrolithiasis-initial results. J Urol. 2001; 166: 2072-80. Erratum in: J Urol 2002; 167: 1805.

6. Sumino Y, Mimata H, Tasaki Y, Ohno H, Hoshino T, Nomura T, et al.: Predictors of lower pole renal stone clearance after extracorporeal shock wave lithotripsy. J Urol. 2002; 168: 1344-7.

7. Ghoneim IA, Ziada AM, Elkatib SE: Predictive factors of lower calyceal stone clearance after Extracorporeal Shockwave Lithotripsy (ESWL): a focus on the infundibulopelvic anatomy. Eur Urol. 2005; 48: 296-302; discussion 302.

8. Danuser H, Müller R, Descoeudres B, Dobry E, Studer UE: Extracorporeal shock wave lithotripsy of lower calyx calculi: how much is treatment outcome influenced by the anatomy of the collecting system? Eur Urol. 2007; 52: 539-46.

9. Elbahnasy AM, Shalhav AL, Hoenig DM, Elashry OM, Smith DS, McDougall EM, et al.: Lower caliceal stone clearance after shock wave lithotripsy or ureteroscopy: the impact of lower pole radiographic anatomy. J Urol. 1998; 159: 676-82.

10. Keeley FX Jr, Moussa SA, Smith G, Tolley DA: Clearance of lower-pole stones following shock wave lithotripsy: effect of the infundibulopelvic angle. Eur Urol. 1999; 36: 371-5.

11. Poulakis V, Dahm P, Witzsch U, de Vries R, Remplik $\mathrm{J}$, Becht E: Prediction of lower pole stone clearance after shock wave lithotripsy using an artificial neural network. J Urol. 2003; 169: 1250-6.

12. Desai MR, Raghunath SK, Manohar T, Prajay S: Lower-caliceal stone clearance index to predict clearance of stone after SWL. J Endourol. 2006; 20: 248-51.

13. Symes A, Shaw G, Corry D, Choong S: Pelvi-calyceal height, a predictor of success when treating lower pole stones with extracorporeal shockwave lithotripsy. Urol Res. 2005; 33: 297-300.

14. Sorensen CM, Chandhoke PS: Is lower pole caliceal anatomy predictive of extracorporeal shock wave lithotripsy success for primary lower pole kidney stones? J Urol. 2002; 168: 2377-82; discussion 2382.

15. Tuckey J, Devasia A, Murthy L, Ramsden P, Thomas D: Is there a simpler method for predicting lower pole stone clearance after shockwave lithotripsy than measuring infundibulopelvic angle? J Endourol. 2000; 14: 475-8.

16. Tiselius HG, Andersson A: Stone burden in an average Swedish population of stone formers requiring active stone removal: how can the stone size be estimated in the clinical routine? Eur Urol. 2003; 43: 275-81.

17. Grasso M, Ficazzola M: Retrograde ureteropyeloscopy for lower pole caliceal calculi. J Urol. 1999; 162: 1904-8. 
18. Pearle MS, Lingeman JE, Leveillee R, Kuo R, Preminger GM, Nadler RB, et al.: Prospective, randomized trial comparing shock wave lithotripsy and ureteroscopy for lower pole caliceal calculi $1 \mathrm{~cm}$ or less. J Urol. 2005; 173: 2005-9.

19. Sampaio FJ, Aragao AH: Inferior pole collecting system anatomy: its probable role in extracorporeal shock wave lithotripsy. J Urol. 1992; 147: 322-4.

20. Gallagher HJ, Tolley DA: 2000 AD: still a role for the intravenous urogram in stone management? Curr Opin Urol. 2000; 10: 551-5.

Correspondence address:

Montserrat Arzoz Fàbregas

USP Instituto Universitario Dexeus

Calle Sabino de Arana, 5-19

Barcelona, 08028, Spain

Fax: + 3493 227-4791

E-mail: 37031maf@comb.es
21. Pace KT, Weir MJ, Harju M, Tariq N, D’A Honey RJ: Individual patient variation and inter-rater reliability of lower calyceal infundibular width on routine intravenous pyelography. BJU Int. 2003; 92: 607-9.

22. Filho DR, Favorito LA, Sampaio FJ: Inferior collecting system anatomy: comparative study between intravenous urogram and three dimensional helical computarizad tomography. J Urol. 2007; 177: (\#431).

Accepted after revision:

December 10, 2008

\section{EDITORIAL COMMENT}

The authors studied the influence of lower pole anatomy on the clearance of lower pole calyceal stone after extracorporeal shock wave lithotripsy (SWL). They found that only lower infundibular height of less than $22 \mathrm{~mm}$ was a favorable factor for a good outcome after SWL. In this study, the stone surface area was $86.1 \mathrm{~mm} 2$ in average. Previous studies showed that lower pole anatomy was important for the choice of treatment of lower pole stone sized $1-2 \mathrm{~cm}$. I agree that the infundibular height is an easy method (cut off: $22 \mathrm{~mm}$ ), nevertheless, several studies also demonstrated the importance of other factors such as infundibular width, infundibular length and mainly infundibulopelvic angle. Sampaio et al. (1) and Lojanapiwat et al. (2) demonstrated the effect of infundibulopelvic angle in the outcome of SWL treatment for lower pole calyceal stone sized between 1 to $2 \mathrm{~cm}(1,2)$. I would suggest that the combination of these factors is still important for understanding this clinical problem.

\section{REFERENCES}

1. Sampaio FJ, D' Anunciacao AL, Silva EC: Comparative follow-up of patients with acute and obtuse infundibulum-pelvic angle submitted to extracorporeal shockwave lithotripsy for lower caliceal stones: preliminary report and proposed study design. J Endourol. 1997; 11: 157-61.

2. Lojanapiwat B, Soonthornpun S, Wudhikarn S: Lower pole caliceal stone clearance after ESWL: Effect of infundibulo-pelvic angle. J Med Assoc Thai. 1999; 82: 891-4.

Dr. Bannakij Lojanapiwat Division of Urology, School of Medicine Chiangmai University

Chiang Mai, Thailand E-mail:blojanap@mail.med.cmu.ac.th 


\section{EDITORIAL COMMENT}

The purpose of this study was the prediction of stone clearance after shock wave lithotripsy (SWL) of small lower pole stones (LPS). In the time before modern endourology with flexible ureterorenoscopy and minimally invasive percutaneous nephrolitotripsy, SWL was with no doubt the treatment of choice in cases of LPS. Following the prospective randomized trials of Albala et al. (1) and Pearle et al. (2), despite their low statistical power, which were both cited in this contribution, stone free rates of SWL seem to be inferior to modern endourological approaches. Therefore, pre-procedure predictive factors are needed to increase predictive stone clearance after SWL and to customize the therapy for each patient, either SWL or an endourological procedure.

There are two principals of pre-procedure prediction, anatomical factors like skin to stone distance, calyx geometries or stone characterization like density (Hounsfield units) or dual source computed tomography.

Until now, several attempts for prediction of stone clearance have been published; however, Knoll et al. (3) showed their insufficient reproducibility by different investigators. However, infundibular height, which was previously published by Tuckey et al. (4) seems to be easily reproducible and could be one of the missing prediction factors for decision of treatment, either effective SWL or an endourological procedure. Studies comparing the infundibular height in intravenous urograms and CT scans would be needed to further see the potential of this method.

\section{REFERENCES}

1. Albala DM, Assimos DG, Clayman RV, Denstedt JD, Grasso M, Gutierrez-Aceves J, et al.: Lower pole I: a prospective randomized trial of extracorporeal shock wave lithotripsy and percutaneous nephrostolithotomy for lower pole nephrolithiasis-initial results. J Urol. 2001; 166: 2072-80. Erratum in: J Urol 2002; 167: 1805.

2. Pearle MS, Lingeman JE, Leveillee R, Kuo R, Preminger GM, Nadler RB, et al.: Prospective, randomized trial comparing shock wave lithotripsy and ureteroscopy for lower pole caliceal calculi $1 \mathrm{~cm}$ or less. J Urol. 2005; 173: 2005-9.

3. Knoll T, Musial A, Trojan L, Ptashnyk T, Michel MS, Alken P, et al.: Measurement of renal anatomy for prediction of lower-pole caliceal stone clearance: reproducibility of different parameters. J Endourol. 2003; 17: 447-51.

4. Tuckey J, Devasia A, Murthy L, Ramsden P, Thomas D: Is there a simpler method for predicting lower pole stone clearance after shockwave lithotripsy than measuring infundibulopelvic angle? J Endourol. 2000; 14: 475-8.

\section{Dr. Udo Nagele Klinik für Urologie Universitätsklinikum Tübingen Tübingen, Germany E-mail:udo.nagele@med.uni-tuebingen.de.}

should be used as a reference. IH is determined on intravenous pyelography. As such, contemporary imaging for the diagnosis of urolithiasis relies primarily on non-contrast CT scan imaging; therefore, the 
information needed to calculate infundibular height may not be available prior to shockwave lithotripsy.

Stone free condition was determined by X-ray and ultrasonography; methods which have faded into historical significance when it comes to imaging to define outcomes in clinical research protocols.

As gender was demonstrated to impact stonefree results, a multivariate analysis controlling for this would be needed to confirm that $\mathrm{IH}$ remains an independent predictor.

Finally, when analyzing infundibular length (IL) and height as components of a right triangle (see figure) the IL line is approximately parallel to AA, which means that angle $\mathrm{B}$ approximately equals the infundibular pelvic angle (IPA).

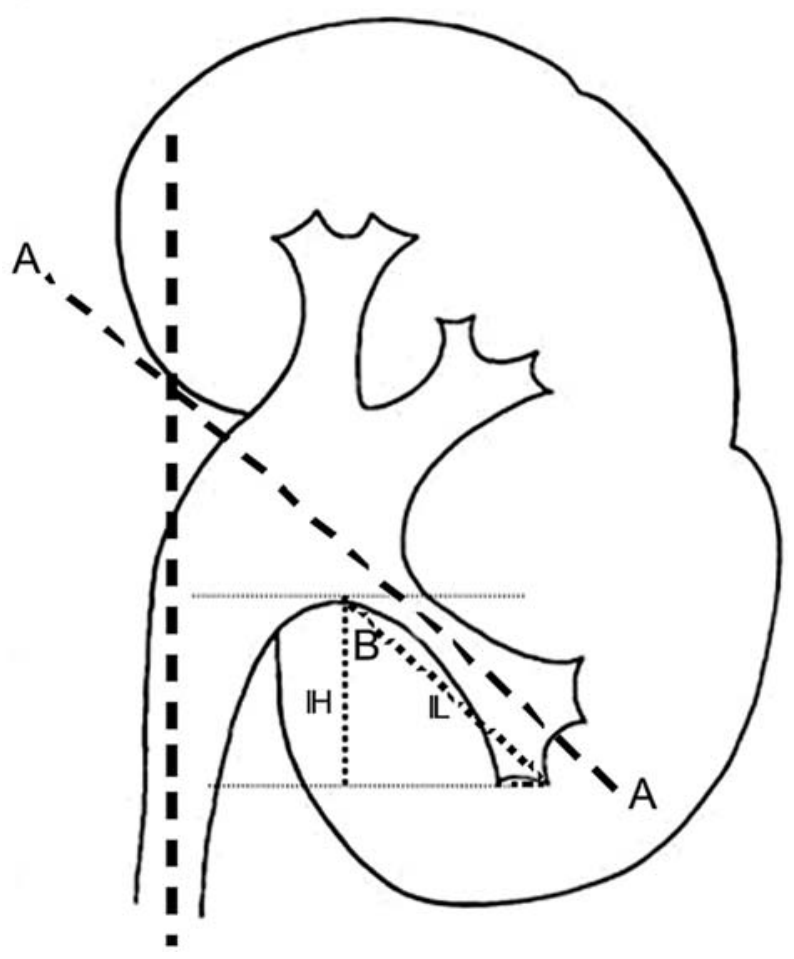

By extending the line at the base of IH from the lowest part of the calyx to the most distal point of the calyx, we have a right triangle with IL as the hypotenuse.

Assuming that angle B equals the IPA then the formula that relates IPA, IH and IL is: $\cos ($ IPA $)=$ $\mathrm{IH} / \mathrm{IL}$ or $\mathrm{IH}=\mathrm{IL} * \cos (\mathrm{IPA})$

Therefore, since the three measures are dependent, given any 2, one should be able to find the third. One would therefore expect that if IH is a predictor of stone clearance, the relationship between IPA and IL would also be a predictor of stone clearance.

Dr. Ricardo Miyaoka, Dr. W. K. Durfee \& Dr. Manoj Monga University of Minnesota Edina, Minnesota, USA E-mail:endourol@yahoo.com 